\title{
Kırgızistan'da Devlet Borçları ve Borç Yönetimi
}

\author{
Tolkun ZHUMAKUNOVA ${ }^{1}$ ve Raziyahan ABDIYEVA ${ }^{2}$
}

$\ddot{O} z$

Kamu borçları çoğu geçiş ekonomili ve gelişmekte olan ülkelerde yapısal sorunlar ve ekonomik büyüme çabaları nedeniyle son 40 sene içerisinde ciddi bir birikime ulaşmıştır. Bu durum borç yönetiminin etkinliğinin arttırılmasıını gerekli kılmaktadır. Günümüzde kamu borçları çoğu geçiş ekonomili ve gelişmekte olan ülkelerin güncel sorunlarındandır. Kırgızistan'da kamu borçları bağımsızlığını kazandığ1 1991 yılından itibaren ciddi kriz ve yapılması gereken ekonomik reformlar dolayısıyla artmıştır. Ülkede yaşanan ekonomik ve siyasi şoklar da devlet borçların yükselmesine neden olmuştur. Kamu borçlarının GSYİH'ya oranı 2008'e kadar düşüş eğiliminde iken, 2008'den sonra yükselerek 2018 yılında \%56 olmuştur. Bu çalışmada Kırgızistan’da kamu borçlarının yönetiminin etkinliği incelenmiştir. Yapılan analizin sonucunda ülkede iç borçların yönetiminde faizlerin yüksek olmasından dolayı borç servisi pahalı olduğu, dış borçların yönetiminde ise kullanımı ile ilgili bilgilerin yeterli derecede saydam olmadığı tespit edilmiştir.

Anahtar Kelimeler: Kamu borçları, Borç yönetimi, Geçiş ekonomileri

\section{Public Debt and Public Debt Administration in Kyrgyzstan}

\section{Abstract}

In recent years public debts have reached a serious level in most countries. Especially in developing countries and transition economies, public debts are constantly increasing in order to accelerate economic growth. This situation increases the relevance of management of public debt. After the dissolution of the USSR, Kyrgyzstan faced serious shocks. During the transition period out of structural and economic reforms public debt increased and reached to 56 percent of GDP in 2018. This study examined the effectiveness of public debt management in Kyrgyzstan. As a result of the analysis, it has been determined that debt service of domestic debt is expensive due to the high interest rates, as about foreign debt the main problems are insufficient transparency of information about its use and low effectiveness of use.

Key Words: Self, Self Esteem, Stress, Coping with Stress, Stress Management

Atıf İçin / Please Cite As:

Zhumakunova, T. ve Abdiyeva, R. (2021). Kırgızistan'da devlet borçları ve borç yönetimi. Manas Sosyal Arastirmalar Dergisi, 10(2), 1070-1082.

Geliş Tarihi / Received Date: 31.10.2019

Kabul Tarihi / Accepted Date: 04.02.2021

\footnotetext{
${ }^{1}$ Kırgızistan-Türkiye Manas Üniversitesi İIBF, tolkun.cumakunova@manas.edu.kg

iD ORCID: 0000-0001-9635-3676

2 Yrd. Doç. Dr. - Kırgızistan-Türkiye Manas Üniversitesi İ̈BF, razia.abdieva@manas.edu.kg

(D) ORCID: 0000-0002-9438-1558
} 


\section{Giriş}

Kamu borçları günümüzde çoğu ülkelerin güncel sorunlarından olarak bilinmektedir. Özellikle, az gelişmiş ülkelerde ekonomik büyümeyi hızlandırmak amacıyla kamu borçları sürekli artmaktadır. Ayrıca, ülke içindeki sermaye yetersizliğinden dolayı daha çok dış borçlanmaya gidilmektedir. Kurgızistan bağımsızlı̆ını kazandığı 1991 yılından sonra çok ciddi şoklarla karşı karşıya kalmıştır. Sovyetler Birliğinin genel bütçesinden gelen transferlerin durdurulması ve eski SSCB ülkeleri ile ticari bağların kopması kamu gelirlerinin önemli ölçüde azalmasına ve üretimin yarı yarıya düşmesine neden olmuştur. Diğer yandan, yapılması gereken yapısal ve ekonomik reformlar ve sosyal harcamalar kamu harcamalarını arttırarak bütçe açığının yükselmesini ve devlet borçlarının artmasını ortaya çıkarmıştır. Çalısmamızın amacı Kırgızistan’da kamu borçlarının ve borç yönetimini incelemektir. Kırgızistan'ın iç ve diş borçların gelişimi ve onların yapısı, çeşitleri, kullanım alanları, borç yükü ve borç yönetimi araştırılmıştır. Girişi izleyen birinci bölümde genel olarak borç kavramı ve borç yönetiminin teorik analizi, ikinci bölümde Kirgızistan'daki genel ekonomik durum, üçüncü bölümde Kırgızistan'da devlet borçlarının analizi, dördüncü bölümde dış borçlar incelenerek sonunda da sonuç ve öneriler sunulmuştur.

\section{Genel Olarak Borç Kavramı ve Borç Yönetimi}

Borç ödünç alınmış herhangi bir şey karşıllı̆ında yerine getirilmesi gereken yükümlülüğü anlatan bir ilişskidir, borçlanma ise, belli bir süre sonra ödenmek üzere para veya benzeri şeylerin ödünç alınmasıdır (Eker ve Meriç, 2000, s. 5; Adıyaman, 2006, s. 22). Kamu borçları ise ekonomik açıdan istikrasızlıklarla mücadele edilmesi, büyüme ve kalkınmanın finansmanın sağlanması gibi nedenlerle başvurulan finansman kaynağıdır (Çaşkurlu, 2003, s. 190). Diğer bir tanıma göre de devlet borçlanması, devletin bir özel hukuk tüzel kişisi olarak isteğe bağlı ve bedel karşllığında, alacaklıya ödenme vaadi ile iç ve dış kaynaklardan elde ettiği gelirdir (Orhaner, 1997, s. 221).

Borçlar sağladıkları kaynak bakımından iç borçlar ve dış borçlar olmak üzere ikiye ayrılmaktadır. Devlet ülke içindeki tüzel ve özel kişilerden veya ülke dışındaki tüzel ve özel kişilerden borçlanabilmektedir. İç borçlar ülke içindeki tasarrufları ve sermayeyi azaltırken dış borçlar milli geliri arttırıcı ve ekonomik büyümeyi hızlandırıcı etkide bulunabilir. Fakat dış borçların çok yüksek seviyelere gelmesi borç servisine olan harcamaların yükselmesini ve sermayenin ülkeden çıkışına neden olabilmektedir. Dolayısıyla borçların ekonomi üzerinde olumsuz etkilerinin önlenmesi ve ekonomik gelişmeyi engellememesi için etkin bir borç yönetimine ihtiyaç duyulmaktadır.

Borç yönetimi belli ekonomik hedeflere ulaşmak amacıyla borç miktarında ve bünyesinde değişiklikler yapılmasıdır. Bu anlamda borç yönetimi, borçların süresi geldiğinde ödenmesidir (Yıldız, 2014, s. 69). Borç yönetimi diğer bir tanıma göre devlet borçlarının etkili bir halde yönetilmesi için bir metod yani strateji geliştirilmesi ve uygulanması sürecidir. En basit tanımı ile etkin borç yönetimi hem en az maliyet hem de en az risk ile piyasalardan fon sağlamasıdır (Ateş, 2002, s. 2).

Borç yönetimi ekonominin genel özellikleri ve yapısına uygun biçimde, alınacak borcun miktarının, ödeme şartlarının, ekonomiye getireceği yükün, borç servis yükünün ağırlaşması durumunda alınabilecek önlemlerin hesaplanmasını kapsar. Etkin borç yönetimi ise, çok az maliyet ve asgari risk ile piyasalardan fon sağlanmasını gerektirir. Etkin bir borç yönetim stratejisinin olmaması kısa vadede sermaye baskılarını arttırmakta ve borç portföyü risk profilinin kötüleşmesine neden olmaktadır (The World Bank, 2007).

Borç yönetimi sürecini üç aşamaya ayırabiliriz. Bunlar: karar alma, kullanma ve geri ödeme aşamalarıdır. İlk aşamada borçlanmanın türü, vadesi ve riskleri ele alınarak herhangi bir borçlanma türüne karar verilecektir. İkinci aşamada elde edilen borçların kullanım alanları belirlenmektedir. Burada şeffaflık ve etkinlik ilkelerine uygun olarak kullanmak önemlidir. Diğer bir değişle, alınan borçların ekonomik gelişmeyi hızlandıracak ve gelir getiren alanlara harcanması borçların geri ödenmesini kolaylaştıracaktır. Bununla birlikte borçların nasıl ve nelere kullanıldığı ile ilgili bilgilerin saydam olması ve raporların sunulması gerekmektedir. Borç yönetimi süreci alınan borçların zamanında geri ödenmesi ile sonuçlanmaktadır. Böylece, borç yönetimi borçları riskleri göz önüne alarak düşük maliyetle sağlamak ve onlar1 etkin kullanarak geri ödemek ile sonuçlanan bir süreçtir.

Etkin bir borç yönetiminin temel unsuru şeffaflıktır. Şeffaflık ise borçlanmanın hem maliyetinin ve riskinin azalmasını sağlayarak, borç yönetimine olan güvenliği arttırarak, dış piyasalardan borç alma imkanını genişletici gibi yatırımcıların finansal yapılarını güçlendirebilme imkanını da sağlar. Bu nedenle 
kamuoyu tarafindan açıkça belirlenebilmesi gerekir ki borçlanma amacının, şartlarının ve borçlanma yoluyla sağlanan kaynakların nasıl kullanıldığı önceden belli olması şartı aranır.

Canbay (2005) Kırgızistan'da borç yönetiminin gelişmesi için borçlanma amacının, şartlarının ve borçlanma yoluyla sağlanan kaynakların nasıl kullanıldığının kamuoyu tarafindan açıkça bilinmesi veya şeffaflı̆̆ın arttırılması gerektiğini bildirmiştir.

Egeli (2008) Kırgızistan’da dış borçların sürdürülebilirliğini 1993-2006 yıllarına ait verileri kullanarak incelemiştir. Birim kök ve eşbütünleşme testlerinin sonucu Kırgızistan'da dış borçların sürdürülebilirliği uluslararası finansal piyasalara bağlı olduğunu, uluslararası faiz oranlarındaki düşmenin dış borcun değerini arttırdığını, ilgili faiz oranlarının yükselmesi ise Kırgızistan'da likidite kısıtını yaratacağını tespit etmiştir. Dolayısıyla, Kırgızistan'da etkin dış borç yönetimi gerekli olduğu sonucunu bulmuşlardır.

Toktosunova (2012) Kırgızistan'da dış borçların etkin yönetim problemlerini incelemiştir. Araştırmanın sonucunda dış borçların ekonomi ve gelir dağılımı üzerinde negatif etkilerinin azaltılması ve borçların etkin yönetimi için ekonomik büyümenin sağlanması gerektiğine işaret etmiştir.

\section{Kırg1zistan'da Temel Ekonomik Göstergeler}

SSCB'nin dağılmasından sonra Kırgızistan ekonomisi 1991-1995 yıllarında ciddi krizle karşı karşıya kalmıştır. Eski SSCB ülkeleri ile ticari bağların kopması, genel bütçeden gelen transferlerin durdurulması ve ortaya çıkan hiper enflasyondan dolayı üretimde \% 50 oranında düşüş yaşanmıştır. Enflasyon, işsizlik ve yoksulluk düzeyi keskin bir şekilde artmıştır. 1991-1995 yıllar krizle mücadele ve reform uygulamaları dönemi olmuştur.

Kırgızistan ekonomisi 1996 yllından itibaren tarım üretimindeki artış ve Kumtör Altın madeninin hizmete sokulması nedeni ile büyümeye başlamıştır (DEİK, 2012, s. 8). Fakat 1998 yllında Rusya'daki mali krizin etkisi ile 1998-1999 yıllarında Gayri Safi Yurtiçi Hasılada (GSYH) düşüş yaşanmıştır. 2000-2001 yıllarında ise Kumtör maden işletmesinin ve tarımın gelişmesi nedeni ile ekonomi \% 5 oranında büyümüştür. 2002'de Kumtör firmasında ortaya çıkan kaza nedeniyle büyüme \% -0.01'e azalmıştır. 2005 yllında ise ülkede yaşanan siyasi darbenin negatif etkilerinden dolayı GSYİH yine -0.1'e küçülmüştür. 2007 ve 2008 yıllarında ihracat, özellikle Çin'den Rusya'ya yeniden ihracatın ve göçmenlerinin transferlerinin artmasından dolayı büyüme $\% 8$ oranında yükselmiştir. 2010 yllında tekrar siyasi darbe ve etnik çatışmaların sonucunda üretimde \% - 0.5'e, 2012'de ise Kumtör altın madencilik firmasının üretimindeki düşüş nedeni ile GSYİH \% -0.1'e azalmıştır. 2013’te söz konusu madencilik firmasının üretiminin artması ile ekonomide $\% 10$ oranında büyüme gerçekleşmiştir.

Dünya piyasalarında petrol fiyatlarında yaşanan azalışlar, petrol ithalatçısı bir ülke olan Kırgızistan'da tüketimi arttırmış, büyümeye de katkıda bulunmuştur. Özellikle altın ihracatındaki ciddi artışlara bağlı olarak ekonomik büyüme hız kazanmıştır. Kırgız mallarına olan talebin azalmasına yol açan ve dolayısıyla 2015 yllında ülkenin altın ihracatı dışındaki ihracatında bir azalış yaşanmasına neden olan Rusya'daki ekonomik durgunluğa rağmen, Kırgıistan ekonomisinde 2014 ylında \% 3.6 olan ekonomik büyüme oran1, büyük ölçüde altın üretimindeki yüksek performansa bağlı olarak, 2015 yllında \% 7.3'e yükselmiştir.

1993 y1lında Kırgızistan'da fiyatların serbest birakılmasıyla enflasyon oranı yüzde 1363'e yükselmiştir. Sıkı para politikaları uygulamalarının sonucunda 1998 yılında yüzde 10'a kadar düşürülmüştür. Ancak, Rusya krizi nedeni ile 1999 yılında enflasyon yüzde 37'ye ulaşmıştır. Sık1 para politikası altında enflasyon 2002-2006 yillarında \% 2 ile 5 arasında sergilemiștir. Fakat 2007-2008 yıllarında global finansal krizin etkisi ile $\% 10,1$ ve $\% 24,5$ 'e yükselmiştir. Son yıllarda enflasyon oranı $\% 6$ ve $\% 7$ civarında tutulmaktadır.

Geçiş döneminin başında üretimin yarı yarıya düşmesi işsizliği hızla artırmıştır. 1992 yllında işsizlerin resmi sayıs1 1,792 iken 1995’te 50,409’a yükselmiştir. İşsizlik oranı resmi istatistiklere göre 1992 ve 2015 döneminde \% 8 ile 9 civarlarında sergilemiştir. Fakat Economic Intelligence Unit'in verilerine göre 2010 yılında toplam 78.150 işsiz kaydedilmiştir. Kırgızistan'da 2010 yllı işsizlik oranı \%20 olmuştur. Çalışabilir nüfus 2.344 milyon iken, kayıtlı nüfustaki işsizlerin $\%$ 14'ünü erkekler, \% 16'sını ise kadınlar oluşturmaktadır (DEİK, 2012, s. 10). Böylece, işsizlik hala ülkenin önemli sorunlarındandır. 
Tablo 1. Kurgızistan'in Temel Ekonomik Göstergeleri

\begin{tabular}{|c|c|c|c|c|c|c|}
\hline Yillar & $\begin{array}{c}\text { GSYİH'nın } \\
\text { büyüme oranı (\%) }\end{array}$ & $\begin{array}{l}\text { Enflasyon } \\
\text { oranı (\%) }\end{array}$ & $\begin{array}{c}\text { İşsizlik oran1 } \\
(\%)\end{array}$ & $\begin{array}{c}\text { İhracat } \\
\text { (milyon \$) }\end{array}$ & $\begin{array}{c}\text { İthalat } \\
\text { (milyon \$) }\end{array}$ & $\begin{array}{l}\text { Toplam D1ş } \\
\text { Borç, } \\
\text { (milyon \$) }\end{array}$ \\
\hline 1992 & $-13,8$ & 1259 & 8,6 & 317,0 & 420,7 & 5,52 \\
\hline 1993 & $-15,4$ & 1363 & 8,7 & 360,2 & 447,8 & 231,83 \\
\hline 1994 & -20 & 95,7 & 8,4 & 340,1 & 317,0 & 368,91 \\
\hline 1995 & $-5,4$ & 31,9 & 8,7 & 408,9 & 531,0 & 485,14 \\
\hline 1996 & 7 & 31,9 & 8,7 & 505,4 & 782,9 & 997,36 \\
\hline 1997 & 9,9 & 23,4 & 8,3 & 603,8 & 646,1 & 1176,06 \\
\hline 1998 & 2,1 & 10,4 & 9,7 & 513,8 & 755,9 & 1329,86 \\
\hline 1999 & 3,6 & 37 & 8,2 & 462,6 & 551,1 & 1545,55 \\
\hline 2000 & 5,4 & 18,7 & 7,5 & 510,9 & 506,9 & 1639,38 \\
\hline 2001 & 5,3 & 6,9 & 7,8 & 480,3 & 440,4 & 1538,03 \\
\hline 2002 & $-0,01$ & 2,1 & 12,5 & 498,1 & 552,1 & 1657,06 \\
\hline 2003 & 7 & 2,9 & 9,9 & 590,3 & 673,0 & 1820,54 \\
\hline 2004 & 7 & 4,1 & 8,5 & 718,8 & 941,0 & 2224,22 \\
\hline 2005 & $-0,1$ & 4,3 & 8,1 & 672,0 & 1101,3 & 1957,58 \\
\hline 2006 & 3,1 & 5,6 & 8,3 & 794,1 & 1718,2 & 2307,71 \\
\hline 2007 & 8,5 & 10,1 & 8,2 & 1134,2 & 2417,0 & 2597,22 \\
\hline 2008 & 8,4 & 24,5 & 8,2 & 1617,6 & 4072,4 & 3333,19 \\
\hline 2009 & 2,9 & 6,8 & 8,4 & 1443,5 & 3040,2 & 3818,96 \\
\hline 2010 & $-0,5$ & 7,9 & 8,6 & 1468,4 & 3385,8 & 3807,33 \\
\hline 2011 & 6 & 16,4 & 8,5 & 2380,7 & 4261,2 & 5174,02 \\
\hline 2012 & $-0,1$ & 2,7 & 8,4 & 2588,3 & 5576,3 & 5705,08 \\
\hline 2013 & 10,9 & 6,6 & 8,3 & 2833,2 & 6069,8 & 6470,51 \\
\hline 2014 & 4 & 7,5 & 8,1 & 2482,7 & 5732,5 & 6949,14 \\
\hline 2015 & 3,9 & 6,5 & 8 & 1606,2 & 4069,5 & 7198,85 \\
\hline 2016 & 4,3 & 0,4 & 7,2 & 1607,9 & 3744,4 & 7929,69 \\
\hline 2017 & 4,6 & 3,2 & 7,1 & 1813,9 & 4197,2 & 8161,33 \\
\hline
\end{tabular}

Kaynak: Dünya Bankası 2014, KC Merkez Bankası Bülteni, Bişkek, 6/2005 ve KC Merkez Bankası Bülteni, Bişkek, 12(251)/2016 ve KC Merkez Bankası Bülteni, Bişkek, 9(260)/2017 verilerine göre hazırlanmıştı.

Dünya piyasalarında petrol fiyatlarında yaşanan azalışlar, petrol ithalatçısı bir ülke olan Kırgızistan'da tüketimi arttırmış, büyümeye de katkıda bulunmuştur. Özellikle altın ihracatındaki ciddi artışlara bağlı olarak ekonomik büyüme hız kazanmışır. Kırgız mallarına olan talebin azalmasına yol açan ve dolayısıyla 2015 yllında ülkenin altın ihracatı dışındaki ihracatında bir azalıs yaşanmasına neden olan Rusya'daki ekonomik durgunluk dolayis1 ile Kirgizistan ekonomisinde 2014 yllinda \% 3.6 ve 2015 yllinda \%3.4 oranında büyüme gerçekleşmiştir.

İhracat bağımsızlı̆̆ kazandıktan sonra 5 kat artmışsa ithalat 9,6 kat artmıştır. Dolayısı ile dış ticaret açığı günümüzde yüksek olmaktadır. İhracatın GSYIH'ya oranı \% 55 civarında iken ithalatın GSYİH'ya oranı \% 80'den fazladır. İhracatın düşük olması ülkenin borçların geri ödemesini daha da zorlaştırabilmektedir.

Bağımsızlı̆ın kazanılması ile daha önce belirtildiği gibi eski SSCB ülkeleri ile ticari bağların kopması ve genel bütçeden gelen transferlerin durdurulmasından dolayı devlet bütçesinde ciddi kaynak sıkıntısı ortaya çıkmıştır. Bu nedenle hükümet 1992 yılından itibaren dış borçları almaya başlamıştır. Dış borç 1992 yllında 5,5 milyon ABD Doları iken 2015 yllında 7198,85 ABD Dolarına ulaşmıştır.

Yukarıdaki Kırgızistan'ın genel ekonomik durumu dikkate alınarak ülkemizin borçlanma nedenlerini aşağıdaki gibi sıralayabiliriz:

- Sovyetler dönemindeki genel bütçeden ayrilan kaynak transferlerinin durdurulmasi;

- Sovyetler dönemi dağılması nedeniyle yapısal reformların finansmanı;

- Sovyetlerin dağılmasılyla ülkeler arası ödeme sisteminin y1kılması, bu sisteminin yıkılmasından dolayı ülkeler arası şirketlerin birbirlerine olan ödemelerindeki gecikmeler;

- Devletin iç borçlanma kaynağının kısıtllilğı;

- Bütçe açıklarının finansmanı;

- Döviz ihtiyac1;

- Sosyal ve altyapı hizmetlerinin üretimi. 


\section{Kırgızistan'da Devlet Borçları}

Kırgızistan'ın bağımsızlığını kazandığı ilk yıllarda kaynak yetersizliğinden dolayı bütçe açı̆̆ı büyümüştür. Bütçe açı̆̆ı 1993-1994 yıllarında GSYİH'ya oranla \% 7 iken, 1995 yılında \% 12'ye çıkmıştır. Fakat 2001 yılında bütçe açı̆̆1 \% 0.4'e kadar azalmıştır (Koyçuyev, 2003, s. 454). 2008'de ekonomideki canlanma ve göçmen transferlerinin yardımı ile bütçe fazla vermiştir.

2009'dan itibaren bütçe açığı hızla artmaya başlamıştır ve 2012'de GSYİH'ya oranla \% 6,6'ya çıkmıştır. 2015’te ise bütçe açı̆̆1 GSYH'ya oranla 1,5’i oluşturmuştur. Bütçe açığ1 Kırgizistan'da daha çok dış borçlanma ile kapatılmaktadır. Kırgızistan'ın toplam dış borç stoku 31 Aralık 2016 tarihi itibariyle 4105.44 milyon dolardır. Bunun \% 92,1’i dış borçlar ve \% 7,9’u iç borçlardan oluşmuştur.

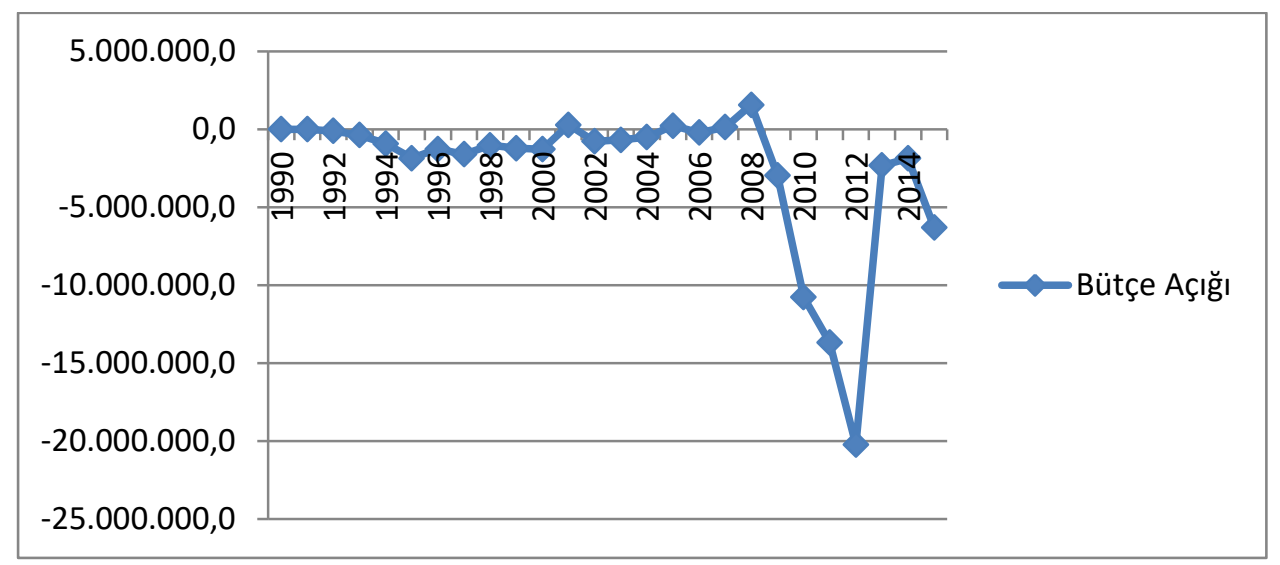

Şekil 1. Kurgı̨istan'da Bütçe Açğı (bin som)

Kaynak: Kırgız Cumhuriyeti İstatistik Komitesi (Erişim tarihi: 05.10.2016)

1993 yılında dış borçların GSYİH'ya oranı \% 7,2 iken 1999 yılında \% 105’e çıkmıştır. Sonraki yıllarda azalarak 2005 yllında \% 76,5 ve 2014'te 46,4’ü oluşturmuştur. Kırgizistan, yüksek dış borcu sebebiyle Dünya Bankası ve IMF tarafından ortak yürütülen Aşırı Borçlu Fakir Ülkeler (HIPC) Programına 2006 yılında başvurarak 1 milyar dolara yakın borcun silinmesi gibi imkânlardan faydalanmayı gözden geçirmiştir. Ancak, bu programa dahil olunmasının prestij kaybına sebep olacağı nedeniyle, ayrıca IMF ve Dünya Bankası'nın ülke ekonomisi üzerinde bulunacağı çeşitli taleplerin yükümlülüğüne girilmek istenmemesinden 2007 yllı Şubat ayında hükümet bu programa dahil olmaktan vazgeçmiştir (DEİK, 2012: 7).

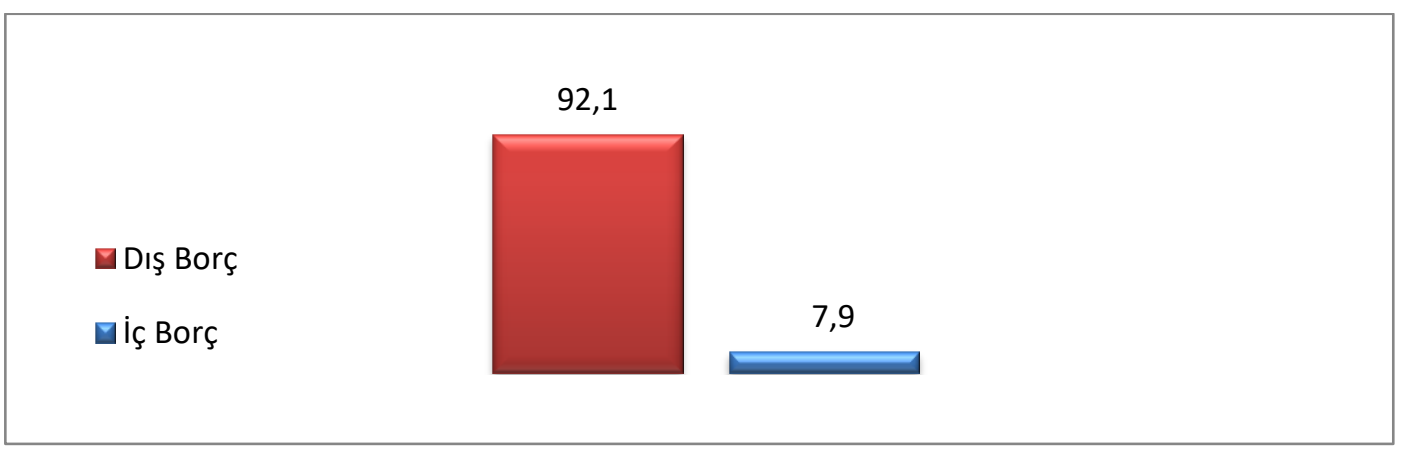

Şekil 2. Kırgı̊istan'da Devlet Borçlarnmn Dă̆ğlmı

Kaynak: Kırgızistan Cumhuriyeti Maliye Bakanlı̆̆ (Erişim tarihi: 20/02/2017)

Bunun dışında 2001 ve 2004 yıllar arasında Paris Klübü ile dış borçların yeniden yapılandırılması ile ilgili anlaşmanın sonucunda dış borç 99 milyon ABD Dolara azalmışıtır (IMF, 2004).

İç borçlar 1998 yılına kadar Merkez Bankadan kredi alarak borçlanırken 1998 yılından sonra bu borç türü durdurulmuştur. Günümüzde iç borç hazine bonoları ve devlet tahvilleri aracilığı ile alınmaktadır. 


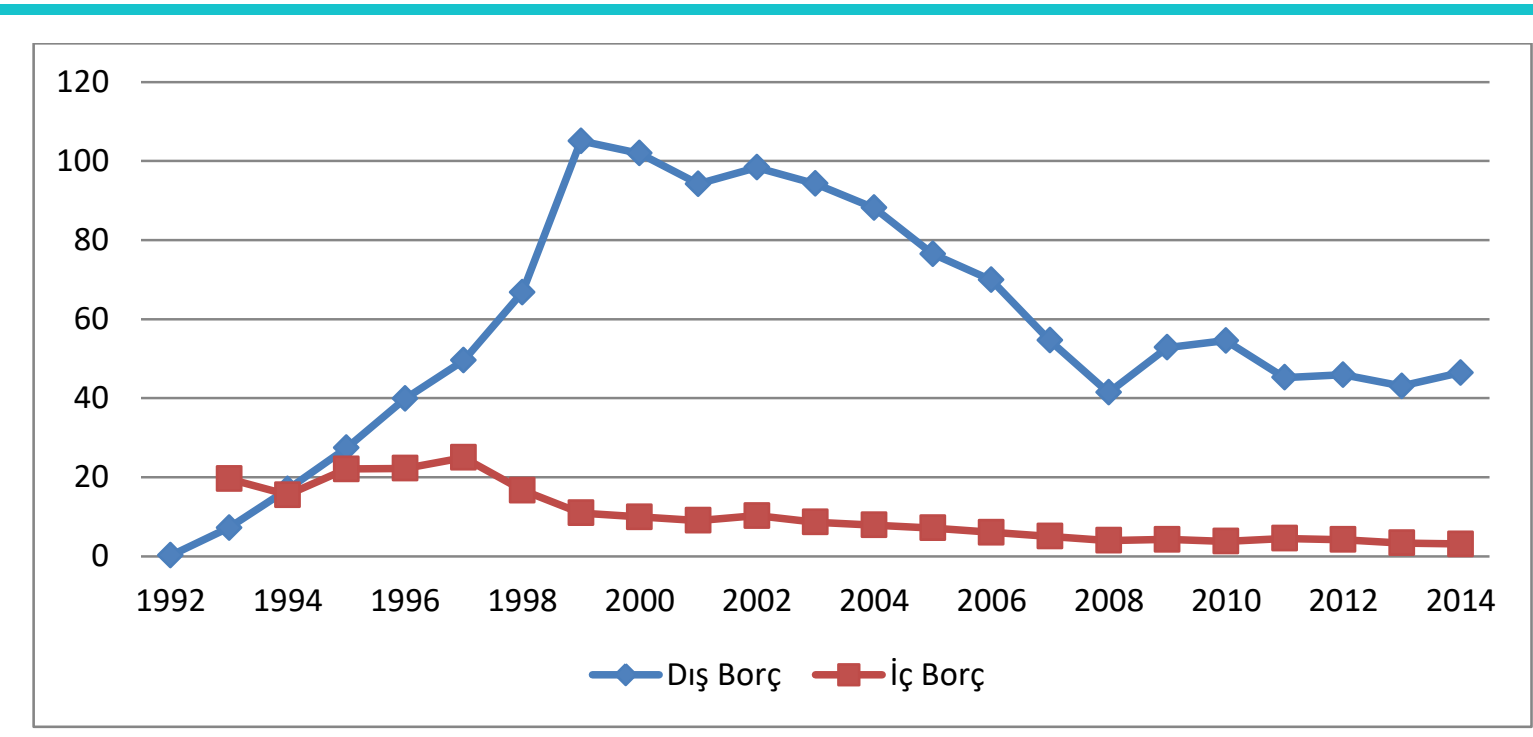

Şekil 3. Kırgızistan'da İs Borçve Dış Borçlarn Gelişimi, (GSYIH'ya oranla)

Kaynak: Kırgızistan Cumhuriyeti İstatistik Komitesi (Erişim tarihi: 10/04/2017)

2014 yllında dış borçlar GSYİH'nın \% 49,5’sini iç borçlar \% 3,1'ini olușturmuştur. Ancak 2015 yllında devlet borçlarının GSYIH'ya oranı \% 64,6'ya yükselmiştir. Bunun nedeni nominal GSYIH'nın seviyesinin beklenildiğinden düşük olduğu ve ulusal paranın değer kaybetmesidir (IMF, 2016, s. 8).

Kırgiz Cumhuriyeti Hükümetinin 6 Ekim 2016 tarihindeki 532 No’lu Kararname ile 2016-2018 yıllarında Kırgız Cumhuriyet'inde Devlet Borçları Yönetimi Stratejisi kabul edilmiştir. Bu stratejide devlet borçlarının yönetiminin temel amaçları Hükümetin finansal ihtiyacını en düşük maliyet ve asgari risk ile karşılama, ülkenin menkul kıymetler piyasasını geliştirmek ve devlet borçlarının sürdürülebilirliğini desteklemektir.

Söz konusu stratejide iç borçlarla ilgili Kırgız Cumhuriyeti Hükümeti devlet iç borç senetlerinin süresini arttırmaya çalışmaktadır. Bunun için hazine bonolarının payını arttırma ve 2 seneden daha fazla vadeli hazine bonolarının çıkartmaya yönelik faaliyetler yapılacaktır. Devletin iç borçlanmasının temel amaçlarından biri menkul kıymetler borsasının gelişmesine katkıda bulunmaktır.

Kırgızistan'da iç borçlar hazine bonoları ve devlet tahvillerinden oluşmaktadır. Hazine bonolarının hacmi giderek arttı̆̆ı görülmektedir. Özellikle 2015 yılında önceki yıla göre 3 kat artmıştır. Bunun en önemli nedenlerinden biri de bu sene hazine bonolarının faiz oranın yüksek olduğu sayılabilir. Ortalama sürelerine bakıldığında daha çok 6 aya kadar kısa süreliler tercih edildiği görülmektedir.

Tablo 2. Kergızisstan'da İ̧ Borçlarnn Dağzllımı

\begin{tabular}{|c|c|c|c|c|c|}
\hline & 2012 & 2013 & 2014 & 2015 & 2016 \\
\hline Hazine Bonoları (milyon som) & 109,1 & 48,1 & 83,1 & 249,7 & 130,8 \\
\hline İşlemler sayıs1 & 11 & 4 & 2 & 10 & 5 \\
\hline $\begin{array}{l}\text { Ortalama ağırlıklı faiz oranı } \\
\text { (bir dönem içinde, \%) }\end{array}$ & 8,53 & 8,48 & 8,45 & 13,38 & 8,14 \\
\hline Ortalama süre (günler) & 174 & 247 & 298 & 185 & 171 \\
\hline Devlet Tahvilleri (milyon som) & - & 98,8 & - & 411,9 & 77,0 \\
\hline İşlemler sayısı & - & 1 & - & 7 & 2 \\
\hline $\begin{array}{l}\text { Ortalama ağırlıklı faiz oranı } \\
\text { (bir dönem içinde, \%) }\end{array}$ & - & 14,59 & - & 14,93 & 15,88 \\
\hline Ortalama süre (günler) & - & 643 & - & 1018 & 342 \\
\hline
\end{tabular}

Kaynak: Kırgız Cumhuriyeti Merkez Bankas1, (Erişim tarihi: 02.03.17).

Devlet tahvillerinde de 2015 yılında daha çok satışların gerçekleştirildiği ve ortalama faiz oranları \% 14-15 arasında olmuştur. 2016 yllında daha çok 1 yl satın alınan devlet tahvillerinin süresinin azaldığı fark edilmiştir. İç borçların faiz oranlarının yüksek olması ülkedeki tasarruf ve sermayeyi çekerek özel sektöre negatif etki verebilir. Diğer bir değişle özel sektörü dışlayabilir. Amerika'da örneğin hazine bonolarının oranı \% 1,27 ile 1,78 oranındadır (US Department of the Treasury, 22.01.18). 
2017 yılında devlet bütçesinden toplam borç servisi için 20,2 milyar som (yaklaşık 290 milyon ABD doları) ayrılacağı planlanmıştır. Bunun 11,2 milyar somu (\% 55’i) dış borçların servisi için ve 8,9 milyar somu da (\% 45’i) iç borçların servisi için harcanacağı planlanmıştır (www.minfin.kg, 10.12.17). Görüldüğg̈ gibi, toplam borçların \% 94'ü dış borçlar olmasına rağmen dış borç ve iç borç servisi için ayrılan para arasında fark azdır. Bunun nedenlerinden biri olarak da dış borçların çoğunun faizi \% 0,75-2,0 iken, iç borçların ortalama ağırlıklı faizi hazine bonoları için \% 8,14; devlet tahvilleri için \% 15,88 olarak çok yüksek olmasıdır. Diğer bir değişle iç borçlar hem servisinin pahalı olması açısından hem de ekonomideki kıt olan boş sermayeyi çektiğinden dolayı ekonomiye negatif etkide bulunmaktadır. Dolayısıyla iç borçların faizinin azaltılması önerilmektedir.

\section{Kırgızistan'ın Dı̧̧ Borçların Yapısı}

Geçiş ekonomilerden olan Kırgızistan'da ülke içindeki kaynak yetersizliğinden dolayı ekonomik gelişme ve bütçe açığını kapatmak amacıyla dış borçlanmaya daha çok başvurulmaktadır. Dış borçların yapısında orta ve uzun vadeli ve imtiyazlı veya düşük faizli dış borçların ağırlık taşıması önemlidir. Borç servis kapasitesini gösteren Kısa Vadeli Dış Borçlar/TDB Oranının \% 15-20 arasında seyretmesi makul karşılanırken \% 20'yi aşmaması tercih edilmektedir (Tandırcıoğlu, 2000, s. 265).

Kırgızistan'da toplam diş borç 1994 yılında 368,9 milyon ABD Doları iken 2015 yllında 7198,9 milyon ABD Dolarına ulaşmışıtır. Kısa vadeli dış borçların payı 1994 yılında \% 2,9 iken 2004 yılında \% 12,8 'e kadar artmıştır. Fakat son yıllarda ve 2015 'te ise kısa vadeli dış borçlar toplam dış borçların \% 4,6'sinı oluşturmuştur.

Tablo 3. Dış Borçlarm Vade Yapısı

\begin{tabular}{|c|c|c|c|c|c|c|}
\hline Yillar & $\begin{array}{c}\text { Toplam Diş } \\
\text { Borç, (milyon } \\
\$ \text { ) }\end{array}$ & $\begin{array}{c}\text { Artış Trendi, } \\
\%\end{array}$ & $\begin{array}{l}\text { Uzun Vadeli } \\
\text { Borçlar }\end{array}$ & $\begin{array}{c}\text { Kisa Vadeli } \\
\text { Borçlar }\end{array}$ & $\begin{array}{l}\text { Uzun Vadeli } \\
\text { Borç/TDB }\end{array}$ & $\begin{array}{l}\text { Kısa Vadeli } \\
\text { Borç/TDB }\end{array}$ \\
\hline 1994 & 368,91 & - & 356,0 & 12,83 & 79,7 & 2,9 \\
\hline 1995 & 485,14 & 31,5 & 472,18 & 12,97 & 77,5 & 2,1 \\
\hline 1996 & 997,36 & 105,6 & 988,70 & 8,66 & 87,0 & 0,8 \\
\hline 1997 & 1176,06 & 17,9 & 1143,04 & 33,02 & 85,2 & 2,5 \\
\hline 1998 & 1329,86 & 13,0 & 1301,67 & 28,19 & 86,5 & 1,9 \\
\hline 1999 & 1545,55 & 16,2 & 1484,88 & 60,68 & 80,1 & 3,3 \\
\hline 2000 & 1639,38 & 6,0 & 1510,37 & 129,02 & 78,0 & 6,7 \\
\hline 2001 & 1538,03 & $-6,2$ & 1490,29 & 47,74 & 81,7 & 2,6 \\
\hline 2002 & 1657,06 & 7,7 & 1646,81 & 10,25 & 84,1 & 0,52 \\
\hline 2003 & 1820,54 & 9,9 & 1783,06 & 37,49 & 83,0 & 1,7 \\
\hline 2004 & 2224,22 & 22,1 & 1896,70 & 327,52 & 74,0 & 12,8 \\
\hline 2005 & 1957,58 & $-12,0$ & 1825,30 & 132,28 & 80,9 & 5,9 \\
\hline 2006 & 2307,71 & 17,9 & 2101,22 & 206,50 & 80,9 & 7,9 \\
\hline 2007 & 2597,22 & 12,5 & 2277,97 & 319,25 & 79,0 & 11,1 \\
\hline 2008 & 3333,19 & 28,3 & 2943,34 & 390,85 & 81,1 & 10,8 \\
\hline 2009 & 3818,96 & 14,6 & 3395,17 & 423,80 & 82,4 & 10,3 \\
\hline 2010 & 3807,33 & $-0,3$ & 3612,39 & 194,94 & 87,8 & 4,7 \\
\hline 2011 & 5174,02 & 35,9 & 4985,95 & 188,07 & 91,0 & 3,4 \\
\hline 2012 & 5705,08 & 10,3 & 5491,54 & 213,54 & 91,1 & 3,5 \\
\hline 2013 & 6470,51 & 13,4 & 6162,75 & 307,77 & 90,6 & 4,5 \\
\hline 2014 & 6949,14 & 7,4 & 6636,31 & 312,83 & 91,4 & 4,3 \\
\hline 2015 & 7198,85 & 3,6 & 6853.94 & 344,91 & 91,3 & 4,6 \\
\hline
\end{tabular}

Kaynak: Fact Fish Verileri (Erişim tarihi: 20/02/2017).

Dış borçların büyük kısmı uzun vadeli borçlardır. Uzun vadeli dış borçların toplam dış borçlardaki pay1 1994 yllında \% 79,7 iken, 2002 yllında \% 84'e ve 2015 yilında da \% 91,3'e ulaşmıştır. Piyasa ekonomisine geçiş sürecinde ekonomik kalkınmanın hızlanması ve sürdürülebilir kalkınmaya ulaşılması için dış borçların büyük kısmı uzun vadeli olması daha uygundur.

\section{Kreditörlere Göre D1ş Borçlar}

Dış borçların kreditörlere göre dağılımına baktığımızda, Kırgızistan'ın en önemli kreditörleri olarak Çin, Uluslararası Kalkınma Birliği, Asya Kalkınma Bankası, Rusya, Japonya, Almanya, Türkiye sayılabilir. Kırgızistan'ın IMF, Asya Kalkınma Bankası ve Uluslararası Kalkınma Birliği'ne olan borcu sırasıyla toplam dış borçların \% 5, \% 15 ve \% 16,3’ü oluşturmaktadır. 2016 yılına ait verilere göre toplam diş borçların \% 7,1'i Rusya, \% 6.2'si Japonya ve \% 2,6’sı Türkiye'den alınan borçlardır. Dış borçların \% 40'ını Çin'den 
alınan borçlar oluşturmaktadır. Kırgız Cumhuriyeti'nin 2016-2018 yıllarında devlet borçlarının yönetimi Stratejisine göre bir kreditöre olan borcun payı toplam dış borçların \% 50'sini aşmamalıdır.

Tablo 4. Kreditörlere Göre Dış Borçlar (milyon dolar)

\begin{tabular}{|c|c|c|c|c|c|c|c|c|c|c|c|c|}
\hline & 2011 & $\%$ & 2012 & $\%$ & 2013 & $\%$ & 2014 & $\%$ & 2015 & $\%$ & 2016 & $\%$ \\
\hline IMF & 181,80 & 6,48 & 190,53 & 6,28 & 202,73 & 6,41 & 185,2 & 5,38 & 188,20 & 5,22 & 188,04 & $\overline{5,0}$ \\
\hline OPEC & 2,03 & 0,07 & 1,31 & 0,04 & 3,94 & 0,12 & 4,00 & 0,12 & 4,51 & 0,13 & 4,84 & 0,1 \\
\hline $\begin{array}{l}\text { Asya } \\
\text { Kalkınma } \\
\text { Bankası }\end{array}$ & 583,36 & 20,8 & 594,65 & 19,6 & 607,07 & 19,2 & 583,6 & 17 & 575,44 & 15,9 & 567,88 & 15,0 \\
\hline $\begin{array}{l}\text { Avrasya } \\
\text { Kalkınma } \\
\text { Bankası }\end{array}$ & - & 0 & - & 0 & - & 0 & 0,38 & 0,01 & 3,53 & 0,09 & 5,48 & 0,1 \\
\hline Avrupa Birliği & - & 0 & - & 0 & - & 0 & - & 0 & 5,44 & 0,15 & 15,81 & 0,4 \\
\hline $\begin{array}{l}\text { Uluslararası } \\
\text { Kalkınma } \\
\text { Birliği }\end{array}$ & 660,49 & 23,6 & 674,84 & 22,3 & 697,09 & 22,0 & 671,5 & 19,5 & 639,29 & 17,7 & 618,21 & 16,3 \\
\hline $\begin{array}{l}\text { İslam } \\
\text { Kalkınma } \\
\text { Bankası }\end{array}$ & 61,05 & 2,17 & 61,72 & 2,03 & 63,95 & 2,02 & 59,02 & 1,72 & 59,48 & 1,65 & 64,59 & 1,7 \\
\hline $\begin{array}{l}\text { Uluslararası } \\
\text { Tarımsal } \\
\text { Kalkınma } \\
\text { Fonu }\end{array}$ & 9,23 & 0,33 & 8,87 & 0,29 & 8,96 & 0,28 & 9,36 & 0,27 & 9,94 & 0,27 & 12,17 & 0,3 \\
\hline $\begin{array}{l}\text { Kuzey } \\
\text { Kalkinma } \\
\text { Fonu } \\
\end{array}$ & 5,95 & 0,21 & 5,93 & 0,19 & 6,06 & 0,19 & 5,21 & 0,15 & 4,57 & 0,12 & 4,31 & 0,1 \\
\hline $\begin{array}{l}\text { Avrupa İmar } \\
\text { ve Kalkınma } \\
\text { Bankası }\end{array}$ & 15,41 & 0,55 & 29,63 & 0,97 & 39,99 & 1,27 & 40,61 & 1,18 & 40,95 & 1,14 & 42,45 & 1,1 \\
\hline Çin & 272,62 & 9,72 & 527,47 & 17,4 & 758,43 & 24,0 & 1115,9 & 32,5 & $\begin{array}{c}1296,4 \\
0\end{array}$ & 36 & $\begin{array}{c}1522,8 \\
3 \\
\end{array}$ & 40,3 \\
\hline Fransa & 5,77 & 0,2 & 5,88 & 0,19 & 6,14 & 0,19 & 5,41 & 0,16 & 4,85 & 0,13 & 4,69 & 0,1 \\
\hline Japonya & 357,38 & 12,8 & 320,56 & 10,6 & 263,21 & 8,33 & 229,4 & 6,67 & 229,0 & 6,35 & 235,9 & 6,2 \\
\hline Almanya & 75,77 & 2,7 & 81,3 & 2,68 & 98,35 & 3,11 & 102,4 & 2,98 & 100,07 & 2,78 & 81,72 & 2,2 \\
\hline Kore & 14,82 & 0,53 & 15,94 & 0,52 & 17,37 & 0,55 & 16,66 & 0,48 & 15,61 & 0,43 & 15,12 & 0,4 \\
\hline Kuveyt & 13,31 & 0,47 & 10,66 & 0,35 & 9,26 & 0,29 & 8,64 & 0,25 & 9,73 & 0,27 & 8,55 & 0,2 \\
\hline Rusya & 300,00 & 10,7 & 300,00 & 9,89 & 300,00 & 9,49 & 300,0 & 8,73 & 300,00 & 8,33 & 270,0 & 7,1 \\
\hline Suudi Fonu & - & 0 & 0,18 & 0,01 & 1,27 & 0,04 & 3,87 & 0,11 & 7,43 & 0,20 & 11,17 & 0,3 \\
\hline Türkiye & - & 0 & 10,00 & 0,33 & 70,54 & 2,23 & 90,00 & 2,62 & 97,00 & 2,69 & 97,0 & 2,6 \\
\hline Abu-Dabi & & & & & 1,06 & 0,03 & 2,64 & 0,08 & 6,42 & 0,18 & 8,76 & 0,23 \\
\hline Danimarka & 3,35 & 0,12 & 3,34 & 0,11 & 3,31 & 0,1 & 3,27 & 0,09 & 3,20 & 0,08 & 3,13 & 0,1 \\
\hline
\end{tabular}

Kaynak: Kırgızistan Cumhuriyeti Maliye Bakanlığı (Erişim tarihi: 20/02/2017).

Dış borçların 2250 milyon ABD doları (\% 59,5) iki taraflı imtiyazlı borçlar, 1481 milyon ABD doları (\% 39,2) çok taraflı imtiyazlı borçlardır. İki taraflı imtiyazsız borç kreditörlerinin ilk sırasında 5,73 milyon dolar $(\% 0,15)$ veren Germes Kreditverziherungs-Aktingezeliaft (Almanya) olmaktadır ve toplam iki taraflı imtiyazsız dış borç stoku 8,86 milyon dolardır (\% 0,23). Çok taraflı imtiyazsız borç ise sadece Avrupa İmar ve Kalkınma Bankasından alınan 42,45 milyon ABD dolar $(\%$ 1,12) tutarındaki borçtur.

Tablo 5. Dıs Borçlarn Yapısı (milyon dolar)

\begin{tabular}{lcccccc}
\hline & 2011 & 2012 & 2013 & 2014 & 2015 & 2016 \\
\hline $\begin{array}{l}\text { İki Taraflı İmtiyazlı Dış } \\
\text { Borçlar }\end{array}$ & 1032190 & 1264385 & 1517662 & 1868054 & 2060478 & 225010 \\
\hline $\begin{array}{l}\text { İki Taraflı İmtiyazsız } \\
\text { Diş Borçlar }\end{array}$ & 250543 & 199967 & 11224 & 10148 & 9267 & 886 \\
\hline $\begin{array}{l}\text { Çok Taraflı İmtiyazlı } \\
\text { Diş Borçlar }\end{array}$ & 1503922 & 1537867 & 1589813 & 1518255 & 1490394 & 148133 \\
\hline $\begin{array}{l}\text { Çok Taraflı İmtiyazsız } \\
\text { Diş Borçlar }\end{array}$ & 15416 & 29632 & 39991 & 40611 & 40951 & 4245 \\
\hline
\end{tabular}

Kaynak: Kırgızistan Cumhuriyeti Maliye Bakanlığı (Erişim tarihi: 20/02/2017). 
Dış borçlar 160 krediden oluşmaktadır. Onların çoğunluğu (\% 98’den fazlası) \% 0,75-2,0 faiz oranı ile imtiyazlı olarak ve geri ödeme süresi de 40 seneye kadar alınmıştır. Avrupa İmar ve Kalkınma Bankasından gelen 10 kredinin dışındaki bütün dış borçlar yukarıda belirtilen faiz oranı ile alınmıştır. En önemli kreditörler olarak Çin, Uluslararası Kalkınma Birliği ve Asya Kalkınma Bankası sayılır. Bunlar devlet dış borçlarının toplam \% 69'unu sağlamıştır. Rusya ve Japonya $\% 8$ ve $\% 6$ faiz oranı ile vererek ikinci sıradadırlar. Bununla birlikte, Rusya 300 milyon dolar borcu 10 sene faizsiz vermiştir (Kırgız Cumhuriyeti 2017 yllının bütçesi, 2016, s. 27).

Çok taraflı borçların nominal değeri 2016 ylı Aralık ayı itibariyle 1523,78 milyon dolardır. Bunun 1481,33 (\% 98,6) milyon ABD doları imtiyazlı iken 42,45 (\% 1,4) milyon doları imtiyazsız borçlardır (Kıgız Cumhuriyeti Maliye Bakanllğı, www.minfin.kg, 31.12.2016). Geri ödeme süresi de 15-40 senedir ve bunun 5-10 senesi ise imtiyazlı iken faizleri genel olarak \% 0,75-2,5 olmaktadır. İki taraflı borçların da çoğunluğu imtiyazlıdır. Geri ödeme süresi 10-30 sene, bunun imtiyazlı süresi 5-10 senedir. Faiz oranları ise \% 0,1-5 olmaktadır (Tsoy, 02/11/2016).

Geçiş döneminde kaynak yetersizliğinden dolayı önemli altyap1 hizmet ve malların üretimi (yol yapmak, elektrik üretimi v.d. hizmetler) dış borçlar aracilığ ile gerçekleştirilmiştir (IMF, 2016, s. 8). Dış borçlar ülkenin tarım sektörüne, sosyal yardımlara, altyapı ve iletişimi geliştirmek ve başka alanlar için harcanmıştır (Koyçumanov ve Osmonaliyev, 2004). Daha ayrıntılı olarak \% 24'ü enerji alanına, \% 24-28’i yol altyapısına, \% 20'si tarım sektörüne ve kalan kısmı ise bütçe açığın kapatmak için harcanmıştır (Kocobayeva, 05/03/2017).

Dış borçların önemli kısmının yol gibi altyapı hizmetleri için harcandığına rağmen Dünya Bankasının verilerine göre Kırgızistan 2013-2014 yıllarında altyapı hizmetlerinin kalitesine göre 148 ülke arasından 108. sıradadır. Ayrıca yolların kalitesine göre 133. sırada, elektrik enerjisi ile ilgili 122. sırada olduğu açıklanmıştır (World Bank, 2014, s. 30).

Dış borçlar alınırken tercih yöntemleri, borçlarla uygulanacak projelerin seçim prosedürü, yapılan fayda maliyet analizleri ve dış borçların kullanım alanları ve alınan sağlanan faydaları hakkında halka detaylı bilgilendirmeler yapılmamaktadır. Dolayısıyla dış borçlar ve genel olarak borçları seçiminde, kullanılacak alan veya projelere karar vermede ve riskleri hesaplayıp en düşük maliyetle en yüksek faydaları sağlayacak, borçları ve projeleri belirleyecek ve borçlar hakkında geniş ve detaylı rapor hazırlayacak borç ofisinin kurulmasi gerekmektedir.

\section{Kırgızistan'da Dış Borç Rasyoları}

Ülkenin çok borçlu olup olmadığı Dünya Bankası tarafından dört kritere göre belirlenmektedir. Bunlar toplam dış borçların GSYİH'ya oranı (TDB/GSYIH), toplam diş borçların ihracata oranı (TDB/İhracat), toplam dış borç servisinin ihracata oranı (TDB Servisi/İhracat) ve toplam dış borç faiz servisinin ihracata oranıdır (TDB Faiz Servisi/İhracat). Bu kriterlerden her biri ayr1 ayr1 olarak değerlendirilir ve üçü çok borçlu rasyosuna ulaşmıssa o ülke çok borçlu ülke olarak sayılır (Sarı, 2004, s. 10).

Tablo 6. Dı̧̧ Borç Göstergeleri

\begin{tabular}{|c|c|c|c|c|c|c|c|c|}
\hline & 2011 & 2012 & 2013 & 2014 & 2015 & 2016 & $\begin{array}{c}\text { Orta } \\
\text { Derecede } \\
\text { Borçluluk } \\
\text { Aralığı }\end{array}$ & $\begin{array}{c}\text { Çok } \\
\text { Borçluluk } \\
\text { Sinır Oranı }\end{array}$ \\
\hline $\begin{array}{l}\text { Toplam Diş Borç } \\
\text { (TDB) Milyon } \\
\text { Dolar }\end{array}$ & 5174,02 & 5705,08 & 6470,51 & 6949,14 & 7198,85 & 3782,74 & - & - \\
\hline TDB/GSYİH & 47,7 & 47,2 & 44,4 & 54,1 & 64,5 & 56,6 & $30-50$ & 50'nin üzeri \\
\hline TDB/İhracat & 230,76 & 295,96 & 322,42 & 368,9 & 489,65 & 244,9 & $165-275$ & 275'in üzeri \\
\hline $\begin{array}{l}\text { TDB } \\
\text { Servisi/İhracat }\end{array}$ & 37,2 & 37,8 & 38,7 & 50,6 & 67,0 & 85,8 & $18-30$ & 30'un üzeri \\
\hline $\begin{array}{l}\text { TDB Faiz } \\
\text { Servisi/Ihracat }\end{array}$ & 18,1 & 16,7 & 16,9 & 21,9 & 25,3 & 31,3 & $12-20$ & 20'nın üzeri \\
\hline
\end{tabular}

Kaynak: Kırgızistan Cumhuriyeti Maliye Bakanlığı, Kırgızistan Cumhuriyeti İstatistik Komitesi (Erişim tarihi: 10/04/2017). 
Tablo 6'da görüldüğü gibi Kırgızistan'ın toplam dış borcunun GSYİH'ya oranına bakıldığında çok borçluluk sınırında olduğu bilinmektedir. Toplam dış borçların ihracata oranı orta borçluluk sınırını aşmamaktadır. Fakat toplam dış borçlar servisinin ihracata oranı çok borçluluk sınır oranından 2,5 kat fazla ve toplam dış borçlar faiz servisinin ihracata oranı çok borçluluk sınır oranından 1,5 kat fazladır. Bu ise dış borçların sürdürülebilirliğinin gelecekte tehlikeli durumda olabileceğinin bir sinyalidir denilebilir.

Dolayısıyla dış borçların yönetimini geliştirmek için yerel sermayenin oluşması ve ihracata yönelik endüstriye yatırım yapılmalıdır. Aynı zamanda dışarıdan çekilen borçların amaca uygun kullanımının kontrol edilmesi gerekmektedir (Osmonaliev ve Koichumanov, 2004).

Borç servisini iyileştirme döviz gelirlerinin arttırılması ile selde edilebilir. Bu amaçla ülkenin uluslararası ticaretteki payını arttırıcı ve alınan kredilerin üretken yatırımlarda kullanılmasını sağlayıcı politikalar uygulaması gerekir. Turizmi geliştirici önlemler alınmalıdır. Dar olan vergi tabanının genişletilmesi, kayıt dışı ekonominin kayıt altına alınması, yatırımları ve üretimi teşvik edici bir vergi politikasının uygulanması gerekmektedir (Canbay, 2005).

Borçların sürdürülebilirliğinin arttırılması için uzun vadeli dış borçları daha etkin ve gelir getirebilen alanlara, diğer bir değişle, ülkenin üretim kapasitesini, özellikle ihracatı arttıran ve işsizliği azaltabilen sektörlerde kullanılması daha uygun olabilir.

\section{Sonuç}

Kırgızistan bağımsızlığını kazandıktan sonra piyasa ekonomisine geçiş sürecinde ciddi krizleri yaşamıştır. Ülke ekonomik ve yapısal reformları gerçekleştirmek ve ekonomik büyümeyi hızlandırmak amacıyla borçlanmak zorunda kalmıştır. Böylece, 1993 yılında dış borçların GSYİH'ya oranı \% 7,2 iken 1999 yllında \% 105’e kadar çıkmıştır.

Günümüzde Kırgızistan'da toplam devlet borçlarının GSYIH'ya oranı (2016 yllına göre) \% 61,5'tir. Bunun \% 4,9'u iç borçlar ve \% 56,6'sı dış borçlardır. Toplam devlet borçlarının ise \% 92'si dış borçlar iken yaklaşık \% 8'i iç borçlardır. Fakat borç servisine harcanan paranın $\% 55$ 'i dış borçlar ve $\% 45$ 'i de iç borçlar için ayrılmaktadır. Bu ise iç borçların faizinin çok yüksek olduğunu göstermektedir. Bunun için iç borçların faizinin önemli derecede azaltılması gerekmektedir.

Yapılan analizler Kırgızistan'ın çok borçluluk sınırını aştığını göstermiştir. Bu göstergeler borçların daha etkin yönetilmesi gerektiğine işaret etmektedir. Borçların yönetimindeki en önemli sorunlardan biri kaynakların kullanımı ile ilgili bilgilerin şeffaf olmamasıdır. Borç yönetiminin geliştirilmesi için borç ofisinin kurulması halka kaynakların kullanımı ve sonuçları ile ilgili raporların hazırlanması, borçları alma ve kullanma kararı verilirken çeşitli bilimsel teknikleri kullanarak alternatifler arasından en uygun olanının seçilmesi açısından faydalı olacaktır.

Borçların yönetiminin güçlendirilmesi için en önemli etken reel sektörün geliştirilmesidir, özellikle döviz gelirlerini arttıran ihracata yönelik üretime odaklanılması, turizmi geliştirmesi ve vergi tabanının genişletilmesi gerekmektedir.

\section{Etik Beyan}

"Kırgı̨istan'da Devlet Borçlar ve Borç Yönetimi” başlıklı çalışmanın yazım sürecinde bilimsel kurallara, etik ve alıntı kurallarına uyulmuş; toplanan veriler üzerinde herhangi bir tahrifat yapılmamış ve bu çalışma herhangi başka bir akademik yayın ortamına değerlendirme için gönderilmemiştir. Bu araştırmada hazır veri seti kullanıldığı için etik kurul kararı zorunluluğu taşımamaktadır.

\section{Kaynakça}

Adıyaman, A. T. (2006). Dış borçlarımız ve ekonomik etkileri. Sayıştay Dergisi, 62, 21-45.

Ateş, G. (2002). Borç yönetimi ofisi ve Türkiye uygulaması üz̧erine bir çalışma. Ankara: T.C Başbakanlık Hazine Müsteşarlığı.

Canbay, T. (2005). Kırgızistan'da dış borç ve borç yönetimi sorunu. Uluslararası Hakemli Sosyal Bilimler E-Dergisi, 6, 1 11.

Çaşkurlu, E. (2003). 1980 sonrası dönemde merkez bankasından kaynak kullanımının makro ekonomik etkilerinin analizi. Gazi Üniversitesi İktisadi ve İdari Bilimler Fakültesi Dergisi, 5(1), 189-208.

DEİK. (2012). Kırgıistan ülke bülteni verileri. Erişim tarihi: 05/10/2016.

Eğeli, H.A. ve Eğeli, H. (2008). 'Bir geçiş ekonomisi olarak kırgızistan'ın dış borçlarının sürdürülebilirliği. Sosyo Ekonomi Dergisi, 4(7), 11-26

Eker, A. ve Meriç, M. (2000). Devlet borçlar. İzmir:Anadolu Matbaası. 

Fact Fish $\quad$ verileri, Internet Adresi:

http:/ ftp.factfish.com/statisticcountry/kyrgyzstan/external\%20debt\%20stocks\%2C\%20short-term, Erişim Tarihi: 20.02.2017. http:/ / ftp.factfish.com/statistic-country/kyrgyzstan/external\%20debt $\% 20$ stocks $\% 2 C \% 201$ long-term, Erişim Tarihi: 20.02.2017

IMF (2004). IMF Staff Country Report No. 04/200, International Monetary Fund, Publication Services, 700 19th Street, N.W. Washington, D.C. 20431, İnternet Adresi: https://www.imf.org/external/pubs/ft/scr/2004/cr04200.pdf, Date of Access: 31.05.17.

IMF, (2016), IMF Staff Country Report No. 16/186, International Monetary Fund, Publication Services, 700 19th Street, N.W. Washington, D.C. 20431.

Kırg1z Cumhuriyeti'nin 2017 yllına göre bütçesi; (2016). Bişkek, İnternet Adresi: http://static2.akipress.org/127/.storage/runews18/files/bff24d80b65062a082a1cb7e73e4f686.pdf, Erişim Tarihi: 13.12.2017

Kırgız Cumhuriyeti Maliye Bakanlı̆̆1 verileri: İnternet Adresi: http://www.minfin.kg/novosti/novosti/na-31dekabrya-2016-goda-razmer-gosdolga-kr-sostav.html, $\quad$ Erişim $\quad$ Tarihi: $\quad$ 31.03.2017. http://www.minfin.kg/ru/novosti/mamlekettik-karyz/gosudarstvennyy-dolg/struktura-gosdolga-posostoyaniyu-na-31-dekabrya-2.html, $\quad$ Erişim $\quad$ Tarihi: 10.04.2017 http://www.minfin.kg/ru/novosti/mamlekettik-karyz/gosudarstvennyy-dolg/struktura-gosudarstvennogodolga-za-yanvar-dekabr-.html, Erişim Tarihi: 10.04.2017.

http://www.minfin.kg/ru/novosti/mamlekettik-karyz/obsluzhivanie-gosudarstvennogo-dolga/za-dvamesyatsa-2017-goda-na-obsluzhivanie-gosdolg.html, Erişim Tarihi: 10.04.2017

Kırg1z Cumhuriyeti Merkez Bankası verileri, İnternet Adresi: http://www.nbkr.kg/index1.jsp?item=137\&lang=KGZ Erișim Tarihi: 02.03.17.

Kırg1z Cumhuriyeti İstatistik Komitesi $\quad$ verileri, Internet http://www.stat.kg/kg/statistics/download/dynamic/516/, $\quad$ Erişim $\quad$ Tarihi: 10.04 .2017$. http://stat.kg/kg/statistics/finansy/, Erişim Tarihi: 05.10.2016

Kocobayeva, Z. (2016). Azatt1k Radyosu http://www.azattyk.org/a/kyrgyzstan_economy_debt/28157315.html, Erişim Tarihi: 05.03.2017.

Koyçuyev, T. (2003). Kırg̨zistan ekonomisi. Bişkek: KTMÜ Matbaası.

Orhaner, E. (1997). Kamu maliyesi. Ankara: Gazi Kitabevi,

Osmonaliev, M. ve Koichumanov, T. (2004). Restructuring Kyrgyzstan external debt: Opportunity Analysis. Central Asia and the Caucasus No. 1(25), Internet Adresi:

file:// C:/Documents $\% 20$ and $\% 20$ Settings/user $\%$ D0 $\% 9 \mathrm{C} \% \mathrm{D} 0 \% \mathrm{BE} \% \mathrm{D} 0 \% \mathrm{~B} 8 \% 20 \% \mathrm{D} 0 \% \mathrm{~B} 4 \% \mathrm{D} 0 \% \mathrm{BE} \% \mathrm{D} 0 \% \mathrm{~B}$ $\mathrm{A} \% \mathrm{D} 1 \% 83 \% \mathrm{D} 0 \% \mathrm{BC} \% \mathrm{D} 0 \% \mathrm{~B} 5 \% \mathrm{D} 0 \% \mathrm{BD} \% \mathrm{D} 1 \% 82 \% \mathrm{D} 1 \% 8 \mathrm{~B} /$ Downloads/restructuring-kyrgyzstan-sexternal-debt-opportunity-analysis.pdf, Date of Access: 10.05.17

Sarı, M. (2004). Dış borc yönetimi ve Türkiye uygulamalar (Uzmanlık Yeterlilik Tezi). Türkiye Cumhuriyeti Merkez Bankası Dış İlişkiler Genel Müdürlüğü, Ankara.

Tandircioğlu, H. (2000). Türkiye'de dış borç sorunu, dış borçların sürdürebilirliği ve dış borçların sınırlandırılması. Dokuz Eylül Üniversitesi SBE dergisi, 2(2), 260-284.

The Ministry of Finance of the Kyrgyz Republic, (2016). Жараандык бюджет, İnternet Adresi:

http://minfin.kg/userfiles/ufiles/2016NPA/zharandyk_byudzhet_saytka.pdf, Erişim Tarihi: 04.05.2017.

Toktosunova, Ç. (2012). Проблемы эффективного управления государственным внешним долгом Кыргызской республики. Reforma Dergisi, 3(55), 36-40.

Tsoy, M. (2013). Veçerniy Bişkek Gazetesi Kaynakları, İnternet Adresi: http://www.vb.kg/doc/226539_vneshniy_dolg_kyrgyzstana_sostavliaet_pochti_poloviny_vvp.html, Erişim Tarihi: 02.11.2016.

US Department of the Treasury, Internet Adresi: https://www.treasury.gov/resource-center/data-chartcenter/interest-rates/Pages/TextView.aspx?data=billrates, Erişim Tarihi: 22.01.18.

Yıldız, F. (2014). Türkiye'de 1990-2012 döneminde kamu borç yönetimi ve kamu borç yapısındaki değişim Üzerine bir inceleme. Sakarya Iktisat Dergisi, 3(2), 67-104.

World Bank; (2007). Managing public debt from diagnostics to reform implementation. Washington, DC: The World Bank Publications.

World Bank; (2014). Kyrgyz Republic - Public expenditure review policy notes: strategic setting. Public Expenditure Review (PER). Washington, D.C.: World Bank Group, İnternet Adresi: http://documents.worldbank.org/curated/en/2015/06/24607685/kyrgyz-republic-public-expenditure-reviewpolicy-notes-strategic-setting, Erişim Tarihi: 03.05.2017.

\section{EXTENDED ABSTRACT}

Nowadays public debts are actual problem of most countries. Public debts are constantly increasing in order to accelerate economic growth, especially in developing countries and transition economies. This situation increases the relevance of management of public debt. After the dissolution of the USSR, Kyrgyzstan faced with serious shocks. During transition period from structural and economic reforms public debt increased and reached to 64.6 percent of GDP in 2015. 
Debt management is changing the amount and structure of debt in order to achieve certain economic goals. (Yildız, 2014, p. 69). Debt management is a method for the effective management of government debts, namely the process of developing and implementing a strategy. In its simplest definition, effective debt management is providing funds from markets with both minimum cost and minimum risk (Ateş, 2002, p. 2).

Transparency is the key element of effective debt management. Transparency reduces the cost and risk of borrowing, increases the security of debt management, and the possibility of borrowing from foreign markets as well as strengthening the financial structure of investors.

After the independence, there was a serious shortage of government revenue due to the deterioration of trade ties with the former USSR countries and the suspension of transfers from the general budget. Hyperinflation and reduction of the production for 50 percent led to decreasing government revenues and sharply rise of budget deficit. Thus foreign government debt was USD 5.5 million in 1992 and it reached USD 7198.85 in 2015.

Exports increased by 5 times, imports increased by 9.6 times after gaining independence. Therefore, foreign trade deficit is high today. While the ratio of exports to GDP is around $55 \%$, the ratio of imports to GDP is more than $80 \%$. The low level of exports can make the repayment of debts more difficult for the country.

In 2014, external debt comprised $49.5 \%$ and internal debt 3.1\% of GDP. However, in 2015, the ratio of government debt to GDP increased to $64.6 \%$. This is due to the fact that the nominal GDP level is lower than expected and the depreciation of national currency (IMF, 2016: 8).

Domestic debts of Kyrgyzstan consist of treasury bills and government bonds. In 2015, average interest rates of government bonds were between 14-15\%. High interest rates of domestic debts may have negative effects on the private sector by attracting savings and capital in the country. In other words, it can exclude the private sector.

In 2017, it is planned to allocate 20.2 billion som (approximately 290 million USD) from the state budget for the total debt service. It is planned that 11.2 billion som $(55 \%)$ will be spent for the service of foreign debts and 8.9 billion som (45\%) will be spent for the service of internal debts (www.minfin.kg, 10.12.17). As can be seen, although $94 \%$ of total debt is foreign debt, the difference between the money allocated for external debt and domestic debt service is small. One of the reasons for this is that the interest of most of the external debt is $0.75-2.0 \%$, while the average weighted interest of domestic debt is $8.14 \%$ for treasury bills and $15.88 \%$ for government bonds. In other words, internal debts have a negative impact on the economy both because of the expensive service and attracting the scarce capital which is scarce in the economy. Therefore, it is recommended to reduce the interest rate of internal debts.

In Kyrgyzstan, external debt is mostly used for covering the budget deficit and economic development due to insufficient resources in the country. In 1994 total foreign debt in Kyrgyzstan was US \$368.9 million; it reached US \$ 7198.9 million in 2015. The share of short-term external debt increased from $2.9 \%$ in 1994 to $12.8 \%$ in 2004 . However, in recent years and in 2015, short-term external debt accounted for $4.6 \%$ of total external debt. Most of the external debt is long-term debt. While the share of long-term external debt in total external debt was $79.7 \%$ in 1994, it reached $84 \%$ in 2002 and $91.3 \%$ in 2015.

According to 2016 data $7.1 \%$ of the total external debt is belonging to Russia, $6.2 \%$ to Japan and $2.6 \%$ to Turkey and $40 \%$ of the foreign debts are from China. Foreign debts consist of 160 credits. The majority (more than 98\%) was concessional with an interest rate of $0.75-2.0 \%$ and the repayment period was taken up to 40 years (Kyrgyz Republic budget for 2017, 2016, p. 27)

During the transition period, due to the lack of resources, production of important infrastructure services and goods (road construction, electricity, production etc.) was realized through external debts (IMF, 2016: 8). External debts have been spent on the country's agricultural sector, social assistance, infrastructure and communication and other fields (Koychumanov, \& Osmonaliyev, 2003). More specifically, $24 \%$ was spent on the energy field, $24-28 \%$ on road infrastructure, $20 \%$ on the agricultural sector and the rest was spent on closing the budget deficit (Kocobayeva, 05/03/2017). 
Although most of the external debt is spent on infrastructure services such as roads, Kyrgyzstan according to World Bank data ranks is 108th among 148 countries in 2013-2014 by the quality of infrastructure services. In addition, it is announced that it ranks 133rd in terms of the quality of roads and 122th in relation to electrical energy (World Bank, 2014, p. 30).

When it comes to external debt, preference methods, selection procedure of the projects to be implemented with debts, benefit cost analyzes and the usage areas of the external debts and the provided benefits are not given to the public in detail. Therefore, it is necessary to establish a debt office which will analyze risks and select that will provide the highest benefits at the lowest cost.

Analyzes showed that Kyrgyzstan has exceeded its indebtedness limit. These indicators point to the need to manage debt more effectively. One of the most important problems in debt management is that information on the use of resources is not transparent. The establishment of a debt office will be useful for the development of debt management, transparency and effectiveness of debt administration.

The most important factor for strengthening the debt management is also development of the real sector, especially focusing on export-oriented production and tourism, which increases foreign exchange revenues and expand tax base. 